\title{
Desenvolvimento das relações entre humildade e gratidão na infância
}

\section{Development of the relations between humility and gratitude in childhood}

\author{
Desarrollo de las relaciones entre humildad y gratitud en la \\ infancia
}

\section{Felipe Queiroz Siqueira*}

Universidade Federal do Rio Grande do Sul - UFRGS, Porto Alegre, Rio Grande do Sul, Brasil

\section{Lia Beatriz de Lucca Freitas**}

Universidade Federal do Rio Grande do Sul - UFRGS, Porto Alegre, Rio Grande do Sul, Brasil

\begin{abstract}
RESUMO
Neste estudo, investigou-se se existe desenvolvimento das relações entre gratidão e humildade na infância. Participaram 28 crianças, distribuídas em três grupos etários (6, 9 e 12 anos), pareadas por sexo. Como instrumento, utilizaram-se duas histórias: em uma delas, o benfeitor foi humilde; na outra, o benfeitor não foi humilde. Cada história foi seguida de uma entrevista semiestruturada. O sentimento de obrigatoriedade de retribuir um favor apresentou variações dependendo do tipo de benfeitor (humilde ou não-humilde). Houve uma maior tendência das crianças mais velhas levarem em conta a humildade e a ausência de humildade do benfeitor, em suas justificativas, quando comparadas com as crianças mais novas. Ao explicitarse a diferença entre as histórias, a frequência de justificativas que mencionaram a falta de humildade do benfeitor aumentou em todas as idades e surgiu o tema da generosidade. Os resultados sugeriram que há desenvolvimento das relações entre gratidão e humildade na infância. Os dados encontrados contribuem para uma reflexão sobre a elaboração de programas educacionais para crianças, especialmente aqueles relacionados a virtudes.
\end{abstract}

Palavras-chave: desenvolvimento, moral, virtudes, humildade, gratidão.

\begin{abstract}
This study examined whether the relations between gratitude and humility develop over childhood. Twenty-eight children, divided into three age groups (6, 9 and 12 years old), participated in this research. We used two vignettes: in one of them, the benefactor was humble; in the other one, the benefactor was not humble. Each story was followed by a semi-structured interview. The feeling of obligation to return a favor showed variations depending on the type of benefactor (humble or non-humble). There was a greater tendency for older children to take into account the benefactor's
\end{abstract}


humility and lack of humility, in their justifications, when compared to younger children. When the differences between the vignettes were made explicit, the frequency of justifications that mentioned the benefactor's lack of humility increased in all ages and the theme of generosity appeared. Results showed that the relations between gratitude and humility develop over childhood. These findings raise questions about the creation of educational programs for children, especially the ones related to virtues.

Keywords: development, morality, virtues, humility, gratitude.

\section{RESUMEN}

Este estudio investigó si hay un desarrollo de las relaciones entre gratitud y humildad en la infancia. Participaron 28 niños, divididos en tres grupos de edad ( 6,9 y 12), emparejados por sexo. Se utilizaron dos historias: en una, el benefactor fue humilde; en la otra, el benefactor no fue humilde. Cada historia fue seguida de una entrevista semi-estructurada. El sentimiento de obligación de retribuir un favor mostró variaciones dependiendo del tipo de benefactor (humilde o no humilde). Hubo una mayor tendencia de los niños mayores tener en cuenta la humildad y la ausencia de humildad del benefactor, en sus justificativas, comparados con los niños más pequeños. Al destacar la diferencia entre las historias, la frecuencia de las justificativas que mencionaron la falta de humildad del benefactor aumentó en todas las edades y la generosidad apareció. Los resultados sugieren un desarrollo de las relaciones entre gratitud y humildad en la infancia. Los datos encontrados contribuyen a una reflexión sobre la elaboración de programas educacionales para los niños, especialmente aquellos relacionados a las virtudes.

Palabras clave: desarrollo, moral, virtudes, humildad, gratitud.

\section{I ntrodução}

Se uma pessoa receber um favor do qual realmente necessita, ela deve ser grata a quem realizou este favor? E se o benfeitor se gabar por tê-la ajudado, ainda assim ela deve ser grata? Estes questionamentos abordam um tema clássico da Filosofia - as virtudes morais -, o qual pode ser encontrado já mesmo em Aristóteles (La Taille, 2000). Na atualidade, pesquisadores de diversas áreas do conhecimento, inclusive da Psicologia, têm-se dedicado ao estudo das virtudes morais, e o interesse pelo assunto aumentou consideravelmente nos últimos anos (Dellazzana-Zanon, Bordini, Sperb, \& Freitas, 2013; Gulliford, Morgan, \& Kristjánsson, 2013). Além da justiça (e.g., Couto \& Alencar, 2015; Rique, Camino, Moreira, \& de Abreu, 2013), tem-se investigado, por exemplo, a generosidade (e.g., La Taille, 2006; Vale, 2012), o amor (e.g., Alves, Alencar, \& Ortega, 2014; Hernandez, Costa, Ribeiro, Areias, \& Santos, 2015) e a gratidão (e.g., Freitas, O'Brien, Nelson, \& Marcovitch, 2012; Freitas, Pieta, \& Tudge, 2011; Morgan \& Gulliford, 2015; Rava \& Freitas, 2013).

Virtudes são qualidades de caráter admiráveis e louváveis atribuídas à pessoa, contrapondo-se assim aos vícios, que também são 
qualidades de caráter, porém desprezíveis e indignas (Dent, 2003). O estudo das virtudes morais é importante, porque elas desempenham um papel fundamental na gênese da moralidade na criança, podendo funcionar tanto como aliadas quanto como adversárias neste processo (La Taille, 2000). Pesquisar virtudes possibilita "identificar novas variáveis psicológicas relacionadas à moralidade humana" (La Taille et al., 1998, p. 11). Segundo Tudge e Freitas (2015), as virtudes desenvolvem-se durante o ciclo vital. Desse ponto de vista, uma pessoa, por exemplo, não é apenas muito ou pouco grata, ela também está em determinado nível de desenvolvimento da gratidão. Nesse sentido, cabe investigar-se o desenvolvimento das virtudes morais desde a infância.

Existem, pelo menos, duas maneiras de se compreender 0 desenvolvimento das virtudes morais (La Taille, 2006): (a) concebese cada uma de modo isolado, pressupondo uma espécie de justaposição entre elas; desta forma, seria possível observar-se modificações em uma virtude sem que haja interferências no funcionamento de outras ou (b) entende-se que as virtudes possuem relações entre si e podem apresentar diversos tipos de intersecção.

Considerando-se que as virtudes morais se desenvolvem ao longo do ciclo vital (Tudge \& Freitas, 2015) e partindo-se da ideia de que existem relações entre elas (La Taille, 2006), investigou-se o juízo moral de crianças acerca de uma possível relação entre gratidão e humildade. Escolheram-se estas duas virtudes em função de que alguns autores (Comte-Sponville, 2000; Emmons, 2007) sugeriram que haveria relação entre elas.

\section{Relações entre gratidão e humildade}

Segundo Comte-Sponville (2000), a pessoa grata reconhece no outro a responsabilidade pela graça recebida, em vez de vangloriar-se, de amar somente a si mesma. Emmons (2007) foi até mesmo mais longe, quando afirmou que a gratidão implicaria a humildade: a gratidão seria o reconhecimento de que um indivíduo não pode ser o que ele é na vida sem a contribuição dos outros.

Nota-se que tanto Comte-Sponville (2000) quanto Emmons (2007) enfocaram apenas a humildade do beneficiário. A gratidão, contudo, origina-se em uma relação entre pessoas (Baumgarten-Tramer, 1938; Comte-Sponville, 2000; Gulliford et al., 2013; McConnell, 1993; Piaget, 1965/1967), podendo emergir quando alguém - o beneficiário - recebe um presente, favor ou ajuda de outra pessoa - o benfeitor. Assim, pode-se pensar que a gratidão requer humildade não apenas do beneficiário, mas também do benfeitor.

Cabe investigar-se ainda se as relações entre gratidão e humildade se modificam ou não. Estudar esta questão é pertinente, visto que há 
evidências de que tanto a gratidão (e.g., Baumgarten-Tramer, 1938; Castro, Rava, Hoefelmann, Pieta, \& Freitas, 2011; Freitas, Mileski, \& Tudge, 2011; Freitas, Pieta, et al., 2011; Rava \& Freitas, 2013; Tudge, Freitas, Wang, Mokrova, \& O’Brien, 2015) quanto a humildade (La Taille et al., 1998) se desenvolvem desde a infância.

\section{Desenvolvimento da gratidão}

De acordo com Freitas et al. (2012), a gratidão pode emergir na relação entre um benfeitor e um beneficiário, na qual um benefício é dado de forma livre (sem o intuito de colocar o beneficiário em dívida) e gratuita (sem retribuição requerida). Ao atribuir boas intenções ao benfeitor, o beneficiário valoriza não apenas a benesse, mas também o próprio benfeitor. O beneficiário, então, sente uma dívida simbólica em relação ao benfeitor e uma necessidade de retribuir o benefício.

Diversos autores (e.g., Bonnie \& de Waal, 2004; Freitas et al., 2012; Piaget, 1965/1967; Rava \& Freitas, 2013) chamaram atenção para o fato de que a gratidão pode dar origem a um ciclo de ajuda e apoio mútuos, visto que o beneficiário inicial, ao retribuir generosamente, possibilita que o ciclo se repita, agora com os papéis invertidos: o benfeitor torna-se beneficiário e vice-versa. Este ciclo, porém, nem sempre acontece de forma completa, conforme ressaltaram Bonnie e de Waal (2004). Uma possibilidade é que a retribuição do favor seja realizada automaticamente, não se levando em consideração os sentimentos envolvidos. Em outras situações, apesar de um sentimento positivo ser despertado, o beneficiário não leva em conta os custos da ação ou as intenções do benfeitor. Em ambos os casos, o beneficiário pode ter uma atitude positiva perante o benfeitor, sem - valorizar. Nestas situações, não surge um sentimento de obrigatoriedade de retribuir o favor.

Pesquisas evidenciaram que alguns aspectos da gratidão evoluem durante a infância e a adolescência: (a) existem formas mais ou menos sofisticadas de gratidão (Baumgarten-Tramer, 1938; Freitas, Pieta, et al., 2011); e (b) as justificativas utilizadas para reprovar a ingratidão modificam-se com o passar dos anos (Freitas, Mileski, et al., 2011). Além disso, dois estudos (Castro et al., 2011; Rava \& Freitas, 2013) constataram que o sentimento de obrigatoriedade de se retribuir o favor evolui ao longo da infância. Nas duas pesquisas, realizadas com crianças de cinco a 12 anos, surgiram três tipos de resposta quando se perguntou se um beneficiário deveria retribuir um favor: (a) deve; (b) pode; e (c) não deve. Para a maioria das crianças - de todas as faixas etárias -, o beneficiário deveria retribuir o favor. O segundo tipo de resposta mais frequente foi o de que ele poderia retribuir, mas não seria necessário. Poucos participantes 
disseram que o beneficiário não deveria retribuir. As justificativas das crianças foram classificadas como: (a) consequência; (b) obrigação heterônoma; (c) bem moral; e (d) não-obrigação. A categoria consequência caracteriza-se pela afirmação de que o beneficiário deveria retribuir devido às consequências - materiais ou psicológicas - que a falta de ajuda acarretaria ao benfeitor. Classificaram-se como obrigação heterônoma as explicações nas quais a retribuição deveria ocorrer para evitar o juízo alheio negativo. Na categoria bem moral, retribuir seria justo, o certo a se fazer e uma maneira de expressar gratidão. Codificaram-se como não-obrigação as justificativas nas quais a retribuição não é (ou não deve ser) uma necessidade. Os resultados desses estudos indicaram que: (a) o enfoque nas consequências para o benfeitor apareceu com maior frequência entre as crianças de 5-6 anos e diminuiu com a idade; (b) a obrigação heterônoma foi o tipo de justificativa com maior frequência e (c) a retribuição como um bem moral surgiu apenas nas respostas de algumas crianças de 11-12 anos. Há evidências de que outras virtudes também se desenvolvem desde a infância. A seguir, apresentam-se características da humildade e indícios de que ela se modifica com o passar dos anos.

\section{Desenvolvimento da humildade}

A humildade é entendida como a consciência extremada dos limites das virtudes e de si (Comte-Sponville, 2000). Uma característica importante desta virtude é o fato de que ela é mais valorizada pelas pessoas quando está em contraste com seus opostos, como a vaidade, o orgulho e a soberba (La Taille, 2009a). Cabe ressaltar que ser humilde não é o mesmo que ser humilhado. A humilhação é uma forma de violência, a qual está frequentemente associada ao sentimento de vergonha (Andrade \& Alencar, 2010).

La Taille (2009a) investigou qual seria a virtude mais importante na visão de jovens paulistanos do Ensino Médio. Apontou-se a humildade como aquela mais relevante pela maioria dos participantes e também foi considerada como aquela que mais faz falta a pessoas famosas consideradas desprezíveis. Atribuiu-se esse resultado ao fato de que a humildade se apresenta como um contraponto à cultura da vaidade, sendo necessária para possibilitar um convívio minimamente harmonioso entre as pessoas.

De acordo com La Taille et al. (1998), ser humilde significa não se gabar dos próprios feitos ou das próprias virtudes. Estes autores realizaram a única investigação encontrada sobre o desenvolvimento da humildade, com crianças de seis, nove e 12 anos. Os resultados indicaram que a palavra humildade foi plenamente conhecida apenas pelas crianças de 12 anos, tendo sido definida como ser modesto ou 
não exibido. Este assunto, contudo, não foi algo estranho às preocupações dos participantes mais novos. A maioria das crianças de seis anos não viu problema algum em fazer publicidade de algo que realmente aconteceu. Para os participantes de 9 e 12 anos, porém, contar para todo mundo sobre seus próprios feitos é um ato reprovável, sendo entendido como "se exibir" ou "se gabar".

O presente estudo teve como objetivo examinar se existe desenvolvimento das relações entre gratidão e humildade na infância. Considerando-se que, na infância, haveria mudanças tanto da forma como as crianças concebem a obrigatoriedade de se retribuir uma benesse (Castro et al., 2011; Rava \& Freitas, 2013) quanto na maneira como elas julgam a publicidade de um feito próprio (La Taille et al., 1998), investigou-se especificamente: (a) se a ausência de humildade do benfeitor (publicidade de seu ato generoso) influencia o sentimento de obrigatoriedade de retribuir o favor do beneficiário; e (b) se esta influência é a mesma para todos ou se o tipo de influência varia de acordo com a idade da criança. Consideraram-se as seguintes hipóteses: (a) para as crianças mais velhas (nove e 12 anos), a ausência de humildade por parte do benfeitor será razão para o beneficiário não retribuir o favor; e (b) a frequência de justificativas que mencionem a falta de humildade do benfeitor aumentará com a idade.

\section{Método}

\subsection{Participantes}

Participaram deste estudo 28 crianças, sendo 13 do sexo masculino $(46,4 \%)$, as quais foram distribuídas em três grupos etários: oito crianças de seis anos (entre $6 ; 2$ e $6 ; 11)^{1}, 10$ crianças de nove anos (entre 9;0 e 9;5) e 10 crianças de 12 anos (entre 12;1 e 12;9). Todos os participantes frequentavam uma escola pública de Porto Alegre-RS, a qual foi escolhida por conveniência.

\subsection{Delineamento}

Realizou-se um estudo evolutivo transversal (Delval, 2002, 2013), o qual se caracteriza por examinar como um determinado fenômeno se modifica com a idade. Priorizou-se uma análise qualitativa dos dados coletados e utilizou-se uma análise quantitativa, a fim de verificar, com maior clareza, se houve diferenças nas respostas dos participantes dos três grupos etários estudados. Cabe observar que o uso de números para investigar diferenças entre grupos etários é utilizado também em pesquisas qualitativas (Marecek, 2003). 


\subsection{I nstrumentos}

Utilizaram-se duas histórias, nas quais ambos os personagens (benfeitor e beneficiário) eram crianças. Em uma das histórias, o benfeitor foi humilde (não deu publicidade a seu ato generoso) e, na outra, não foi (divulgou sua ajuda). Após cada história, realizou-se uma entrevista individual semiestruturada com a criança, tendo como referência o método clínico (Alencar \& Ortega, 2003; Delval, 2002; Piaget, 1926/2005). As histórias e as perguntas básicas da entrevista foram as seguintes:

História do Paulo. Paulo não sabia jogar bola. Um menino viu e, então, ensinou Paulo. O menino não contou para ninguém que tinha ensinado Paulo. Na próxima semana, esse menino precisava fazer um trabalho em grupo no colégio, mas não tinha sido convidado por ninguém. Paulo tem que [deve] convidar o menino para o seu grupo ou não? Por quê? Se Paulo não convidar, tem algum problema ou não? Se tu fosses o Paulo, tu convidarias ou não? Por quê? (versão feminina: Paula)

História do Lúcio. Lúcio não sabia jogar bola. Um menino viu e, então, ensinou Lúcio. Depois, esse menino saiu contando para todo mundo que tinha ensinado Lúcio. Na próxima semana, esse menino precisava fazer um trabalho em grupo no colégio, mas não tinha sido convidado por ninguém. Lúcio tem que [deve] convidar o menino para o seu grupo ou não? Por quê? Se Lúcio não convidar, tem algum problema ou não? Se tu fosses o Lúcio, tu convidarias ou não? Por quê? (versão feminina: Lúcia)

De acordo com La Taille (2009a), a humildade é mais valorizada quando contrastada com seus opostos. Por isso, realizou-se uma comparação explícita entre as histórias. Após ressaltar as diferenças entre os dois personagens, fizeram-se mais alguns questionamentos.

Comparação explícita. Essas duas histórias são parecidas, mas têm uma diferença: O menino que ensinou Paulo "não contou para ninguém"; o menino que ensinou Lúcio "saiu contando para todo mundo". Tu achas que tanto Paulo quanto Lúcio [não] têm que convidar o menino para entrar no grupo ou será que um tem que convidar e o outro não? Se "os dois" ou "nenhum", perguntar: Por quê? Se "apenas um", perguntar: Qual o que deve: Paulo ou Lúcio? Por quê? (versão feminina: Paula e Lúcia) 


\section{Procedimentos}

\subsection{Coleta de dados}

Antes de dar início à pesquisa propriamente dita, testaram-se os instrumentos por meio de dois estudos: (a) um pré-piloto, realizado com um menino ( 6 anos) e duas meninas ( 9 e 10 anos) e (b) um piloto, conduzido com nove crianças, de ambos os sexos, distribuídas igualmente nos três grupos etários. Esses estudos possibilitaram verificar a compreensão das histórias e das perguntas pelas crianças, assim como permitiram adequá-las à sua linguagem.

Durante a pesquisa, entrevistaram-se as crianças em sala adequada, localizada na própria escola. A ordem de apresentação das histórias foi sistematicamente modificada. As entrevistas foram gravadas e posteriormente transcritas, gerando um protocolo para cada participante.

\subsection{Análise de dados}

Realizou-se uma análise de conteúdo, considerando-se os passos sugeridos por Delval (2002): (a) leitura de todas as entrevistas para obter-se uma visão geral dos dados; (b) escolha aleatória de algumas entrevistas de cada grupo etário para serem relidas, buscando-se identificar tipos de resposta, com o objetivo de construir categorias provisórias de análise; (c) releitura de todas as entrevistas, procurando classificar as respostas dos participantes de acordo com essas categorias iniciais; e (d) realização de ajustes, se necessário. $\mathrm{Na}$ criação das categorias, seguiu-se o modelo misto (DellazzanaZanon, 2014): (a) partiu-se de categorias encontradas na literatura sobre o desenvolvimento da gratidão (Castro et al., 2011; Freitas, Mileski, et al., 2011; Rava \& Freitas, 2013) e da humildade (La Taille et al., 1998) e (b) durante o processo de interpretação dos dados, quando necessário, modificaram-se essas categorias ou criaram-se novas. Dois juízes categorizaram os dados e, quando houve discordância, realizou-se um acordo entre eles. Finalmente, realizouse um levantamento de frequência das respostas e das justificativas dos participantes, em cada um dos grupos etários.

\subsection{Considerações éticas}

O presente estudo seguiu as diretrizes e normas da Resolução 466/2012 do Ministério da Saúde, o qual dispõe sobre pesquisas realizadas com seres humanos. O projeto de pesquisa foi enviado ao Comitê de Ética em Pesquisa do Instituto de Psicologia da Universidade Federal do Rio Grande do Sul, tendo sido aprovado sob o número 636.999. A direção da instituição de ensino assinou a autorização para a realização da pesquisa, os pais ou responsáveis 
legais assinaram um Termo de Consentimento Livre e Esclarecido (TCLE) e as crianças assinaram um Termo de Assentimento.

\section{Resultados}

Em primeiro lugar, apresentam-se os resultados sobre o sentimento de obrigatoriedade de convidar os benfeitores humilde e nãohumilde. Em segundo, expõem-se os dados encontrados na comparação explícita entre as histórias.

Em ambos os casos, ilustram-se as categorias de análise com extratos das entrevistas. Todos os trechos são seguidos por: (a) história a qual faz referência ( $\mathrm{HP}=$ história do Paulo; $\mathrm{HL}=$ história do Lúcio; e $\mathrm{CPL}=$ comparação entre os dois personagens); (b) o número de identificação do participante; e (c) a idade do participante em anos e meses, respectivamente. Por exemplo, (HL, P13, 12;4) significa: História do Lúcio, Participante 13, 12 anos e 4 meses. Denominaram-se outras as respostas dos participantes que não puderam ser classificadas em nenhuma das categorias de análise, porque "não ficaram suficientemente claras para que fossem codificadas" (Freitas, Mileski et al., 2011, p. 11). Quando se discorre sobre as frequências encontradas, utilizam-se porcentagens em função de que nem todos os grupos etários têm o mesmo número de participantes.

\subsection{Sentimento de obrigatoriedade de convidar os benfeitores humilde e não-humilde}

Nas duas histórias, encontraram-se três tipos de respostas à pergunta "Ele tem que convidar o menino para o seu grupo ou não?": (a) deve; (b) pode e (c) não deve. A categoria deve abarcou as respostas nas quais a criança afirmou que o beneficiário (Paulo ou Lúcio) deveria convidar o menino. Por exemplo: Sim, porque a Lúcia fez um favor pra ela, de ajudar ela, então a Lúcia tem que contribuir (HP, P13, 12;4). Classificaram-se como deve mesmo aquelas respostas em que o participante ponderou outras possibilidades, desde que ele tenha concluído que o melhor seria fazer o convite. Por exemplo: Tanto faz se ela queria ou não convidar, mas eu acho que ela deveria (HP, P23, 12;8). Na categoria pode, incluíram-se as respostas das crianças que julgaram que o beneficiário (Paulo ou Lúcio) poderia convidar o menino, mas não existiria a necessidade de que o fizesse. Por exemplo: Ela não teria a obrigação de convidar aquela menina pro grupo, pra fazer o trabalho junto com ela, só porque ensinou ela a jogar bola (HP, P10, 12;5). Codificaram-se como não deve as respostas em que, para a criança, não haveria razão para o beneficiário convidar o menino. Por exemplo: Não. [...] 
Porque ela saiu contando pra todo mundo ( $\mathrm{HL}, \mathrm{P} 32,6 ; 8)$. A seguinte resposta foi classificada como outras: "Eu não sei se é o caso, mas eu acho que sim e não" (HL, P11, 12;4).

A maioria das crianças afirmou que o beneficiário deveria convidar o menino para o grupo: $89 \%$ na história Paulo (com humildade) e $71 \%$ na história do Lúcio (sem humildade). Um menor número de participantes indicou que ele poderia escolher entre convidar ou não: $11 \%$ (história do Paulo) e 3,5\% (história do Lúcio). Entretanto, seis crianças $(21 \%$ da amostra) consideraram que o beneficiário não deveria convidar o menino, sendo que este tipo de resposta apareceu apenas na história do Lúcio (sem humildade) e aumentou de frequência com a idade: $12,5 \%$ ( 6 anos), $20 \%$ ( 9 anos) e $30 \%$ (12 anos).

Analisaram-se, a seguir, as justificativas das crianças para suas respostas. As justificativas sobre por que o beneficiário (Paulo ou Lúcio) deveria convidar o menino para seu grupo foram classificadas em cinco categorias: (a) consequência, (b) amizade, (c) reciprocidade, (d) bem moral e (e) presença de humildade. A categoria consequência (Con.) compreendeu justificativas nas quais 0 menino teria por objetivo evitar uma consequência negativa para o benfeitor prévio. Por exemplo: Porque se ele ficasse sem grupo, ele não ia poder fazer o trabalho da escola $(H L, P 26,9 ; 1)$. Ele pode ficar triste (HL, P16, 6;5). A categoria amizade (Ami.) abarcou as explicações dos participantes que consideraram que o beneficiário deveria convidar o menino, porque eles seriam ou poderiam se tornar amigos. Nessas justificativas, considerou-se a relação entre os dois personagens (benfeitor e beneficiário), não se centrando em apenas um deles, como na categoria anterior. Por exemplo: Porque daí elas vão ser amigas, e quanto mais amiga a gente tem melhor a nossa vida fica (HP, P32, 6;8). Alguns participantes indicaram, inclusive, que convidar o menino seria uma maneira de evitar que o vínculo entre beneficiário e benfeitor fosse afetado. Por exemplo: Daí ela pode ficar meio chateada, braba com a Lúcia, se a Lúcia não quiser ajudar ela a fazer o trabalho em grupo (HL, P13, 12;4). A categoria reciprocidade (Rec.) abrangeu justificativas nas quais convidar 0 menino seria uma forma de devolver-lhe a benesse. Nessa categoria, porém, a motivação para o convite não ficou clara, ou seja, o participante não mencionou se o beneficiário levou em consideração os sentimentos envolvidos, se houve avaliação dos custos da ação ou das intenções do benfeitor, nem se a retribuição foi motivada por elementos externos à consciência ou por convicções internas. Por exemplo: A menina foi gentil com ela, ela podia ser gentil com ela também (HL, P19, 9;1). Na categoria bem moral (BMo.), incluíram-se as justificativas nas quais o convite ao menino seria uma forma de retribuição, uma maneira de expressar gratidão pelo favor recebido. Nessas justificativas, a motivação para convidar o benfeitor prévio 
estaria baseada em convicções internas e não em exigências socialmente impostas. Para o participante, a retribuição seria um valor: seria justo, seria bom retribuir.

Por exemplo:

Pode ser um modo de agradecer pelo que ela fez, ajudando a Lúcia a jogar bola. [...] Porque quando a gente agradece a gente sabe que... Quando a gente recebe um agradecimento, a gente sabe como foi bom o que a gente fez. Que ajudou e vai se sentir melhor, porque tu fez uma coisa boa (HL, P12, 12;5).

$\mathrm{Na}$ categoria presença de humildade (PHu.), incluíram-se as justificativas em que o menino deveria ser convidado porque ele não deu publicidade ao fato de ter ensinado o beneficiário a jogar futebol. Por exemplo: Porque esse menino que ensinou o Paulo a jogar bola não contou pra ninguém (HP, P18, 9;0).

Alguns participantes citaram mais de um tipo de justificativa. Por exemplo, codificou-se a seguinte resposta como amizade e consequência. Participante: Porque os melhores amigos sempre ajudam os melhores amigos. [...] Entrevistador: Se o Paulo não convidar, tem algum problema ou não? Participante: Sim, daí o menino vai ficar chateado (HP, P34, 6;2).

Classificaram-se como não-obrigação (NOb.) todas as justificativas em que os participantes indicaram que o beneficiário (Paulo ou Lúcio) apenas poderia convidar o menino para seu grupo, pois ele não teria obrigação de fazê-lo. Apresenta-se um exemplo a seguir. Participante: Se ela não quiser, não precisa. Entrevistador: Se a Paula não convidar, tem algum problema ou não? Participante: Não. Entrevistador: Por que não? Participante: Porque ela não tá fazendo uma coisa ruim, só não convidou (HP, P19, 9;1).

As justificativas dos participantes que avaliaram como indesejável ou não recomendável convidar o menino foram agrupadas na categoria ausência de humildade (AHu.). Todas as crianças referiram-se à publicidade dada pelo benfeitor a seu ato generoso. Por exemplo: Porque ele saiu contando pra todo mundo: [...] Ah, ensinei o Lúcio. Ah, ensinei o Lúcio ( $H L, P 28,9 ; 5)$. Algumas avaliaram que ele tinha se gabado: Porque ela se exibiu muito (HL, P22, 12;6).

Classificou-se como outras a seguinte explicação: "Eu não sei se é o caso, mas eu acho que sim e não. Porque seria chato o cara se achar porque ajudou, saiu contando para todo mundo, ajudei ele, sei ajudar todo mundo agora" ( $\mathrm{HL}, \mathrm{P} 11,12 ; 4)$. A Tabela 1 mostra a frequência, por grupo etário, dos tipos de justificativa sobre a obrigatoriedade de convidar o benfeitor, em ambas as histórias. 
Tabela 1

Frequência das Justificativas Sobre a Obrigatoriedade de Convidar os Benfeitores Humilde e Não-Humilde por Grupo Etário

\begin{tabular}{lccccccccc}
\hline \multicolumn{10}{c}{ História do Paulo (com humildade) } \\
\hline & Con. & Ami. & Rec. & BMo. & PHu. & NOb. & AHu. & Outras & Total \\
\hline 6 anos & 3 & 5 & 1 & 0 & 0 & 0 & 0 & 0 & 9 \\
9 anos & 4 & 1 & 3 & 0 & 1 & 1 & 0 & 0 & 10 \\
12 anos & 0 & 3 & 3 & 1 & 1 & 2 & 0 & 0 & 10 \\
Total & 7 & 9 & 7 & 1 & 2 & 3 & 0 & 0 & 29 \\
\hline \multicolumn{8}{c}{ História do Lúcio (sem humildade) } \\
\hline 6 anos & Con. & Ami. & Rec. & BMo. & PHu. & NOb. & AHu. & Outras & Total \\
\hline anos & 2 & 1 & 0 & 0 & 0 & 0 & 1 & 0 & 10 \\
12 anos & 0 & 1 & 3 & 0 & 0 & 0 & 2 & 0 & 10 \\
Total & 6 & 7 & 8 & 1 & 0 & 1 & 3 & 1 & 10 \\
\hline
\end{tabular}

\subsection{Sentimento de obrigatoriedade na comparação entre as histórias}

Encontraram-se três tipos de respostas em relação à pergunta "Tu achas que tanto Paulo quanto Lúcio têm que convidar o menino para entrar no grupo ou será que um deles tem que convidar e o outro não?": (a) ambos, (b) Paulo e (c) nenhum. A resposta de uma menina ilustra o primeiro tipo: Eu acho que as duas tem que convidar as duas, porque foi um favor que as duas fizeram para a Paula e para a $[\ldots]$ Lúcia (CPL, P13, 12;4). Quanto às crianças que afirmaram que apenas Paulo deveria convidar o benfeitor humilde para seu grupo, segue um exemplo: $O$ Lúcio não e o Paulo sim. Porque [...] o guri que ensinou o Lúcio começou a contar pra todo mundo ( $C P L, P 25,9 ; 0)$. $\mathrm{Na}$ comparação entre as histórias, também surgiu a ideia de que não existiria a necessidade de se convidar o menino, tivesse sido ele humilde ou não. Por exemplo: $\mathrm{Eu}$ acho que as duas não são obrigadas a convidar (CPL, P10, 12;5).

A maioria das crianças (61\%) afirmou que Paulo e Lúcio deveriam convidar os meninos - humilde e não-humilde, respectivamente para o grupo. Dez participantes (36\%) indicaram que apenas Paulo deveria realizar o convite ao menino (humilde). A frequência deste tipo de resposta aumentou com a idade: $25 \%$ (6 anos), $40 \%$ (9 anos) e $40 \%$ (12 anos). Apenas uma criança disse que não haveria necessidade de se convidar seja Paulo seja Lúcio.

Examinaram-se as justificativas das crianças para suas respostas. As justificativas de que tanto Paulo quanto Lúcio deveriam convidar o menino para o grupo foram classificadas em quatro categorias: (a) consequência (Con.), (b) amizade (Ami.), (c) reciprocidade (Rec.) e (d) generosidade (Gen.). As três primeiras foram semelhantes às apontadas anteriormente na análise. A seguir, exemplifica-se cada uma delas. Consequência: Se ninguém ajudar elas, não vão aprender 
nada, não vão aprender matemática, não vão saber a data, o abecedário ( $\mathrm{CPL}, \mathrm{P31}, 6 ; 11)$. Amizade: Porque eles podem virar amigo na escola ( $C P L, P 15,6 ; 5)$. Reciprocidade: Porque foi um favor que as duas fizeram pra Paula e pra [...] Lúcia. Fizeram esse favor, então as duas podem contribuir fazendo um trabalho com elas em grupo (CPL, P13, 12;4). A nova categoria - generosidade compreendeu as justificativas em que ambos os beneficiários (Paulo e Lúcio) deveriam fazer o convite, porque tanto o benfeitor humilde quanto o não-humilde haviam prestado um favor. Por exemplo: Participante: Eu acho que tem que convidar o menino que ensinou ele a jogar bola. Entrevistador: Quem? Paulo, Lúcio ou os dois? Participante: Os dois. Entrevistador: Por quê? Participante: Porque $[\ldots]$ os meninos ajudaram eles (CPL, P36, 12;4).

Com relação aos participantes que indicaram que apenas Paulo deveria convidar o menino para o grupo, todas as justificativas foram categorizadas como presença de humildade (PHu.). Por exemplo:

Eu acho que faz mais sentido a Paula convidar, porque a menina não tinha contado pra ninguém. E a menina que ajudou a Lúcia contou pra todo mundo. Aí, quando ela contou pra todo mundo, a outra ficou até... Escutou aquilo como se fosse uma brincadeira, um deboche (CPL, P12, 12;5).

Menciona-se o exemplo de uma justificativa classificada como outras: "Eu acho que as duas não são obrigadas a convidar. Porque essa menina que ajudou a Lúcia saiu contando para todo mundo, porque ela devia ter alguma carência no momento ou na vida dela" (CPL, P10, 12;5). A Tabela 2 mostra a frequência, por grupo etário, dos tipos de justificativa sobre a obrigatoriedade de convidar os benfeitores humilde e não-humilde, quando se compararam as histórias.

Tabela 2

Frequência das Justificativas na Comparação entre as Histórias por Grupo Etário

\begin{tabular}{lccccccc}
\hline & Con. & Ami. & Rec. & Gen. & PHu. & Outras & Total \\
\hline 6 anos & 1 & 5 & 0 & 0 & 2 & 0 & 8 \\
9 anos & 0 & 0 & 4 & 1 & 3 & 2 & 10 \\
12 anos & 0 & 0 & 2 & 2 & 4 & 2 & 10 \\
Total & 1 & 5 & 6 & 3 & 9 & 4 & 28 \\
\hline
\end{tabular}

\subsection{Discussão}

A investigação de relações entre as virtudes permite entender a moralidade humana como um sistema, sem que as partes estejam meramente justapostas. Alguns autores (Comte-Sponville, 2000; Emmons, 2007) sugeriram que gratidão e humildade estariam relacionadas, e há evidências de que essas virtudes se desenvolvem desde a infância (e.g. Baumgarten-Tramer, 1938; Castro et al., 
2011; Freitas, Pieta, et al., 2011; La Taille et al., 1998; Rava \& Freitas, 2013; Tudge et al., 2015). Assim, realizou-se um estudo sobre o juízo moral de crianças de 6, 9 e 12 anos, a fim de examinar se existiria um desenvolvimento das relações entre gratidão e humildade também na infância.

$\mathrm{Na}$ amostra investigada, os resultados indicaram que, para algumas crianças, em todas as faixas etárias pesquisadas, o beneficiário não necessita retribuir o favor quando o benfeitor dá publicidade a seu ato generoso. Em outras palavras, constatou-se que também entre as crianças mais novas a falta de humildade do benfeitor pode influenciar o ciclo da gratidão (Bonnie \& de Waal, 2004; Freitas et al., 2012; Piaget, 1965/1967; Rava \& Freitas, 2013), visto que o beneficiário pode não lhe atribuir boas intenções.

No entanto, conforme esperado (segunda hipótese deste estudo), verificou-se que, com a idade, aumentou a porcentagem de participantes que julgaram que não se deve retribuir o favor ao benfeitor não-humilde, uma vez que ele havia dado publicidade ao favor prestado. Este achado é congruente com pesquisas (e.g., Graham, 1988; La Taille et al., 1998; Piaget, 1932/1994) cujos resultados indicaram que as crianças menores tendem, com maior frequência que as mais velhas, a desconsiderar as intenções do agente em seus juízos morais.

Os dados encontrados também sugerem que, desde a infância, a falta de humildade do benfeitor, e não apenas do beneficiário (ComteSponville, 2000; Emmons, 2007), pode influenciar o ciclo de gratidão. Quando se considera que a gratidão se origina em uma relação entre pessoas, é importante que se conduzam investigações tanto do ponto de vista de quem dá quanto de quem recebe.

Cabe observar ainda que o desenvolvimento da relação entre a humildade e a gratidão tornou-se mais evidente, quando se compararam explicitamente as duas histórias. Na amostra deste estudo, a humildade apareceu em praticamente um terço das justificativas. Verificou-se também um aumento, com a idade, da porcentagem de crianças que citaram o tema da humildade para justificar seja a retribuição ao benfeitor humilde seja a não obrigatoriedade de retribuir ao benfeitor sem humildade. Conforme sugeriu La Taille (2009a), a humildade parece ser mais valorizada quando contrastada com seus opostos (a vaidade e o orgulho).

O conjunto desses achados ressalta, mais uma vez, a importância da humildade para um convívio minimamente harmonioso entre as pessoas (Noguchi \& La Taille, 2008). Vale lembrar que, na tradição da cultura Ocidental, até mesmo propagar fatos positivos a respeito de si é mal visto (La Taille et al., 1998). Na contemporaneidade, porém, exibir-se e gabar-se é quase um imperativo para diversas pessoas (La Taille, 2009b; Llosa, 2013), o que tem contribuído para tornar as relações sociais agressivas e violentas (La Taille, 2009a). 


\section{Considerações finais}

Os resultados deste estudo sugerem que há um desenvolvimento das relações entre gratidão e humildade na infância. Uma limitação desta pesquisa é o pequeno número de participantes da amostra. Seria necessário utilizar amostras representativas da população para verificar se o padrão de desenvolvimento encontrado se manteria ou se, pelo contrário, os achados seriam restritos aos participantes deste estudo.

Apesar disso, os resultados obtidos contribuem para que se compreenda melhor como ocorre a evolução da moralidade humana, especificamente no que diz respeito ao desenvolvimento das virtudes morais. Pesquisas como esta possibilitam a elaboração de programas educacionais para as crianças, principalmente no que se refere às virtudes, que sejam adequadas ao nosso contexto. A formação moral exige estratégias próprias (Couto \& Alencar, 2015) e os professores necessitam ter acesso a estudos que auxiliem a construção de práticas adequadas em sala de aula. Para o delineamento desses programas, é fundamental contar com pesquisas produzidas em diversos campos do conhecimento, inclusive, da psicologia (Carr \& Harrison, 2015).

A partir dos resultados deste estudo, entende-se que seria importante investigar empiricamente, além da humildade do benfeitor, a do beneficiário. Como os dados encontrados indicam que há relações entre gratidão, humildade e generosidade, sugere-se ainda examinar essas relações de maneira mais aprofundada em futuras pesquisas. Abordou-se a relação entre humildade e gratidão, e há estudos que enfocaram a relação entre gratidão e generosidade (e.g., Vale, 2012). Todavia, não se encontraram pesquisas que investigassem as três virtudes de forma integrada.

\section{Referências}

Alencar, H. M., \& Ortega, A. C. (2003). O método clínico no estudo da moralidade humana. In S. R. F. Enumo, S. S. Queiroz, \& A. Garcia (Eds.), Desenvolvimento humano e aprendizagem (pp. 121-140). São Paulo: Casa do Psicólogo.

Alves, A. D., Alencar, H. M. de, \& Ortega, A. C. (2014). Moralidade e concepção de amor em crianças de 6 e 9 anos. Revista Psicopedagogia, 31(94), 21-34.

Andrade, A. N., \& Alencar, H. M. (2010). Juízo de pessoas surdas sobre humilhação: passado e presente. Revista Semestral da Associação Brasileira de Psicologia Escolar e Educacional, 14(2), 271-280. 
Baumgarten-Tramer, F. (1938). "Gratefulness" in children and young people. The Pedagogical Seminary and Journal of Genetic Psychology, 53(1), 53-66. doi: 10.1080/08856559.1938.10533797

Bonnie, K. E., \& de Waal, B. M. (2004). Primate social reciprocity and the origin of gratitude. In R. A. Emmons \& M. E. McCullough (Eds.), The psychology of gratitude (pp. 213-229). New York: Oxford University Press.

Carr, D., \& Harrison, T. (2015). Educating character through stories. Exeter: Imprint Academic.

Castro, F. M. P., Rava, P. G. S., Hoefelmann, T. B., Pieta, M. A. M., \& Freitas, L. B. de L. (2011). Deve-se retribuir? Gratidão e dívida simbólica na infância. Estudos de Psicologia (Natal), 16(1), 7582. doi: 10.1590/S1413-294X2011000100010

Comte-Sponville, A. (2000). Pequeno tratado das grandes virtudes. São Paulo: Martins Fontes.

Couto, L. L. M., \& Alencar, H. M. de. (2015). Educação moral no Ensino Fundamental: Prática docente de ensino da justiça. Psico, 46(1), 90-100. doi: 10.15448/1980-8623.2015.1.16927

Dellazzana-Zanon, L. L. (2014). Projetos de vida na adolescência: Comparação entre adolescentes que cuidam e que não cuidam de seus irmãos menores (Tese de doutorado). Porto Alegre: Universidade Federal do Rio Grande do Sul.

Dellazzana-Zanon, L. L., Bordini, G. S., Sperb, T., \& Freitas, L. B. L. (2013). Pesquisas em desenvolvimento moral: Contribuições da psicologia brasileira. Psico, 44(3), 342-351.

Delval, J. (2002). Introdução à prática do método clínico: Descobrindo o pensamento das crianças. Artmed.

Delval, J. (2013). O desenvolvimento psicológico humano. Petrópolis: Vozes.

Dent, N. J. H. (2003). Virtude. Dicionário de ética e filosofia moral. São Leopoldo: Unisinos.

Emmons, R. (2007). Thanks!: How the new science of gratitude can make you happier. New York: Houghton Mifflin Harcourt.

Freitas, L. B. de L., Mileski, A. Z., \& Tudge, J. R. H. (2011). O juízo moral das crianças sobre a ingratidão. Aletheia, 34, 6-18.

Freitas, L. B. de L., Pieta, M. A. M., \& Tudge, J. R. H. (2011). Beyond politeness: The expression of gratitude in children and adolescents. Psicologia: Reflexão e Crítica, 24(4), 757-764. doi: 10.1590/S0102-79722011000400016

Freitas, L. B. de L., O'Brien, M., Nelson, J. A., \& Marcovitch, S. (2012). A compreensão da gratidão e teoria da mente em crianças de 5 anos. Psicologia: Reflexão e Crítica, 25(2), 330338. doi: 10.1590/S0102-79722012000200015 
Graham, S. (1988). Children's developing understanding of the motivational role of affect: An attributional analysis. Cognitive Development, 3(1), 71-88.

Gulliford, L., Morgan, B., \& Kristjánsson, K. (2013). Recent work on the concept of gratitude in philosophy and psychology. The Journal of Value Inquiry, 47(3), 285-317. doi:10.1007/S10790013-9387-8

Hernandez, J. A. E., Costa, S. V., Ribeiro, J. R., Areias, C. A., Santos, K. N. V. (2015) Autorrelatos do amor no ciclo vital adulto. Estudos e Pesquisas em Psicologia. 15(2), 747-763.

La Taille, Y. (2000). Para um estudo psicológico das virtudes morais. Educação e Pesquisa, 26(2), 109-121. doi:10.1590/S151797022000000200008

La Taille, Y. (2006). A importância da generosidade no início da gênese da moralidade na criança. Psicologia: Reflexão e Crítica, 19(1), 9-17. doi: 10.1590/S0102-79722006000100003

La Taille, Y. (2009a). As virtudes segundo os jovens. In Y. La Taille \& M. S. S. Menin (Eds.), Crise de valores ou valores em crise? (pp. 46-69). Porto Alegre: Artmed.

La Taille, Y. (2009b). Formação ética: Do tédio ao respeito de si. Porto Alegre: Artmed.

La Taille, Y., Micelli, A., Domingues, C. B., Kravosac, D. B., Jamra, F. A., Fiorini, F. P., Bronstein, M., \& Nete, S. O. (1998). As virtudes morais segundo as crianças (Relatório Científico FAPESP não-publicado). São Paulo: Instituto de Psicologia da USP.

Llosa, M. V. (2013). A civilização do espetáculo: Uma radiografia de nosso tempo e de nossa cultura. Rio de Janeiro: Objetiva.

Marecek, J. (2003). Dancing through minefields: Toward a qualitative stance in psychology. In P. M. Camic, J. E. Rhodes, \& L. Yardley (Eds.). Qualitative research in psychology: Expanding perspectives in methodology and design (pp. 49-69). Washington, DC: American Psychological Association.

McConnell, T. C. (1993). Gratitude. Philadelfia: Temple University Press.

Morgan, B., \& Gulliford, L. (2015, Janeiro). Measuring virtuous gratitude. Apresentado em Jubilee Centre for Character and Virtues 3rd Annual Conference, Oxford. Disponível em http://www.jubileecentre.ac.uk/502/papers

Noguchi, N. F. C., \& La Taille, Y. (2008). Universo moral de jovens internos da Febem. Cadernos de Pesquisa, 133, 11-40.

Piaget, J. (1967). Études sociologiques. Genève: Librairie Droz. (Original publicado em 1965)

Piaget, J. (1994). O juízo moral na criança. São Paulo: Grupo Editorial Summus. (Original publicado em 1932) 
Piaget, J. (2005). A representação do mundo na criança. Aparecida: I déias \& Letras. (Original publicado em 1926)

Rava, P. G. S., \& Freitas, L. B. L. (2013). Gratidão e sentimento de obrigatoriedade na infância. Psico-USF, 18(3), 383-394. doi: 10.1590/S1413-82712013000300005

Rique, J., Camino, C., Moreira, P., \& de Abreu, E. (2013). Julgamento moral de jovens em diferentes contextos políticos. Arquivos Brasileiros de Psicologia, 65(2), 243-257.

Tudge, J. R. H., \& Freitas, L. B. L. (2015). Gratitude is not only the greatest of virtues, but the parent of all others: The development of the virtue of gratitude in different societies. Apresentado em Jubilee Centre for Character and Virtues 3rd Annual Conference, Oxford. Disponível em http://www.jubileecentre.ac.uk/502/papers

Tudge, J. R. H., Freitas, L. B. L., Wang, Y. C., Mokrova, I. L., \& O'Brien, M. (2015). The wishes and expression of gratitude of youth. Paidéia, 25, 281-288. doi: 10.1590/198243272562201501

Vale, L. G. (2012). Desenvolvimento moral: A generosidade relacionada à justiça e a gratidão (Tese de doutorado). São Paulo: Universidade de São Paulo.

\section{Endereço para correspondência \\ Felipe Queiroz Siqueira}

Universidade Federal do Rio Grande do Sul

Instituto de Psicologia

Rua Ramiro Barcelos, 2600, sala 118, Santana, CEP 90035-003, Porto Alegre - RS, Brasil

Endereço eletrônico: felipeqsiqueira@gmail.com

\section{Lia Beatriz de Lucca Freitas}

Universidade Federal do Rio Grande do Sul

Instituto de Psicologia

Rua Ramiro Barcelos, 2600, sala 118, Santana, CEP 90035-003, Porto Alegre - RS, Brasil

Endereço eletrônico: Iblf@ufrgs.br

Recebido em: 30/11/2015

Reformulado em: 25/05/2016

Aceito para publicação em: 27/05/2016

\section{Notas}

* Mestre em Psicologia pela Universidade Federal do Rio Grande do Sul (UFRGS), doutorando do Programa de Pós-Graduação em Psicologia da UFRGS, com apoio financeiro da CAPES, e membro do Laboratório de Psicologia e Epistemologia Genética (LAPEGE).

** Doutora em Psicologia pela Universidade de São Paulo (USP), professora do Programa de Pós-Graduação em Psicologia da Universidade Federal do Rio Grande do Sul (UFRGS), onde coordena o LAPEGE - Laboratório de Psicologia e 
Epistemologia Genética, bolsista de produtividade do CNPq e membro do grupo de pesquisa More than Thank You e do GT da ANPEPP Psicologia e Moralidade.

${ }^{1}$ Optou-se por indicar as idades dos participantes por dois números separados por ponto-e-vírgula, representando os anos e os meses, respectivamente. Por exemplo, os números $6 ; 2$ indicam que a criança tem 6 anos e 2 meses. 